\title{
DOS EJEMPLOS DE CHALET EN MÉRIDA A MEDIADOS DEL SIGLO XX: LOS COMIENZOS EN LA OCUPACIÓN DE UN ENTORNO ARQUEOLÓGICO
}

\author{
MARÍA DEL ROSARIO CASTRO CASTILLO \\ Museo Nacional de Arte Romano
}

\begin{abstract}
Resumen
En el presente artículo ofrecemos un estudio acerca de dos proyectos para chalet que se llevaron a cabo en Mérida (Badajoz) a finales de los años cuarenta y cincuenta del siglo XX, enmarcados dentro del panorama arquitectónico general de aquella época en España para viviendas de familias acomodadas. A través de ellos puede verse la coexistencia de líneas tradicionales con otras que se esfuerzan por ser novedosas, en un momento en el que los arquitectos recién titulados tienen su inspiración fundamental en historicismos nacionales o en movimientos europeos previos. Los proyectos estudiados corresponden una zona de expansión poblacional, donde la adecuación de las actuaciones urbanas y arquitectónicas al entorno arqueológico que las sustenta, en el caso de las ciudades históricas, se convierte en un reto que tardará, en ocasiones, decenios en materializarse.
\end{abstract}

Palabras clave

Mérida, urbanismo, arquitectura, siglo XX, chalet, vivienda, expansión, tradicional, moderno.

\section{TWO EXAMPLES OF A VILLA IN MÉRIDA IN THE MIDDLE OF THE 20TH CENTURY: THE BEGINNINGS IN THE OCCUPATION OF AN ARCHAEOLOGICAL ENVIRONMENT}

\begin{abstract}
In the present article we offer a study about two projects for a villa that were carried out in Mérida (Badajoz) at the end of the 40s and 50s of the 20th century, framed within the general architectural panorama of that time in Spain for family dwellings Accommodated. Through them can be seen the coexistence of traditional lines with others that strive to be novel, at a time when the newly qualified architects have their fundamental inspiration in national historicisms or in previous European movements. The projects studied correspond to an area of population expansion, where the adaptation of urban and architectural actions to the archaeological environment that sustains them, in the case of historic cities, becomes a challenge that will sometimes take decades to materialize.
\end{abstract}

\section{Key words}

Merida, urbanism, architecture, 20th century, chalet, housing, expansion, traditional, modern. 
En el presente artículo vamos a realizar el estudio de dos chalets construidos en Mérida durante los años cuarenta y cincuenta del siglo XX en las proximidades de un yacimiento tan importante como es el circo romano. Como ciudad histórica que es, Mérida no puede sustraerse al peso en ocasiones verdaderamente aplastante de su pasado arqueológico, llegando a constituir este legado patrimonial un verdadero problema a la hora de afrontar el inevitable crecimiento del caserío, tanto en el interior como más allá de los límites de la ciudad tradicional. Esta circunstancia, unida a otras de igual relevancia en el caso de Mérida, como la existencia de los ríos Guadiana y Albarregas y la presencia imponente de la vía férrea, dará lugar a que el progresivo crecimiento y urbanización de la ciudad se vean continuamente constreñidos en unos límites muy concretos, teniéndose que adoptar durante bastante tiempo, como consecuencia, soluciones provisionales y sin planificación en muchos de los casos - colmatación de espacios, hacinamiento...- antes de poder dar el salto definitivo fuera de estas fronteras perimetrales. Para el caso concreto que nos ocupará - el entorno del circo romano $^{-}$, su urbanización se produce de forma tardía dada su lejanía al centro tradicional, lo que nos recuerda que el monumento se encontraba, ya desde su misma construcción en época imperial romana, también en los extrarradios de la urbe, circunstancia que se va a mantener más de dos mil años después.

Desde el punto de vista demográfico, el importante crecimiento de la población emeritense a finales del siglo XIX está provocado fundamentalmente por la afluencia inmigratoria que, desde el comienzo de los trabajos de construcción del ferrocarril y su llegada a la ciudad en 1864, se instala en ella. A partir de ese momento -aunque con altibajos en algunos períodos conflictivos de la primera mitad del siglo XX-, en Mérida aumentarán los sectores secundario y terciario con rapidez, pero sin perder de vista el peso fundamental que la agricultura tenía en ellos. La ciudad afianza así su tradicional papel como nudo de comunicaciones, dando continua salida y entrada a mercancías y, cómo no, a población llegada al calor del trabajo. El crecimiento demográfico que se derivó, como consecuencia, dio lugar a que ya a finales del siglo XIX las autoridades proporcionaran soluciones a esta urgente necesidad de viviendas planificando zonas de expansión que pronto se evidenciaron insuficientes.

La población inició bajo supervisión municipal su crecimiento en este momento por el noroeste, para continuar por las zonas sur y suroeste. Sin embargo, a partir de las grandes excavaciones arqueológicas que tuvieron lugar en Mérida a partir de 1910, las necesidades expansionistas urbanas se verán muy condicionadas por la conservación del ingente patrimonio arqueológico que, sobre todo en la zona meridional, se está protegiendo, con la prohibición de construir en áreas arqueológicas y la aparición continua de restos. A partir de este momento, los diferentes posicionamientos mantenidos por el Ayuntamiento y la Dirección General de Bellas Artes se evidenciarán de forma constante. Intervenciones como las llevadas a cabo según el Proyecto de Abastecimiento y Saneamiento de los ingenieros de caminos Casimiro Juanes Clemente y Ramón Montalbán y García Noblejas, en 1923, el de Alineaciones, Rasantes y de Ensanche de Antonio Gómez Millán y Leopoldo Carrera, en 1927, o el de Trazado, Abastecimiento y Saneamiento del Ensanche de Celestino y Colsa, en 1943, convivirán con esta problemática y serán una buena muestra de las actuaciones emprendidas por los poderes municipales en su búsqueda continua de un adecuado desarrollo urbanístico y arquitectónico.

A mitad de siglo, la puesta en marcha del Plan Badajoz aprobado en el año 1952 dará lugar a una nueva revitalización económica, al igual que antes, centrada en la producción y transformación de productos agrícolas, lo que vuelve a traducirse en una masiva llegada de población a la ciudad. En este momento, la imperiosa necesidad de viviendas da como resultado que el Ayuntamiento y los particulares se impliquen en la superación de los límites urbanísticos que aprisionaban el caserío emeritense, promoviendo distintas intervenciones al otro lado de las mismas, con el levantamiento de barrios dedicados a funcionarios y obreros. El Plan General de Ordenación Urbana de García-Pablos y Bailly, de 1954, será el proyecto más importante de este momento. Aunque no se llegó a desarrollar completamente, se realizó 


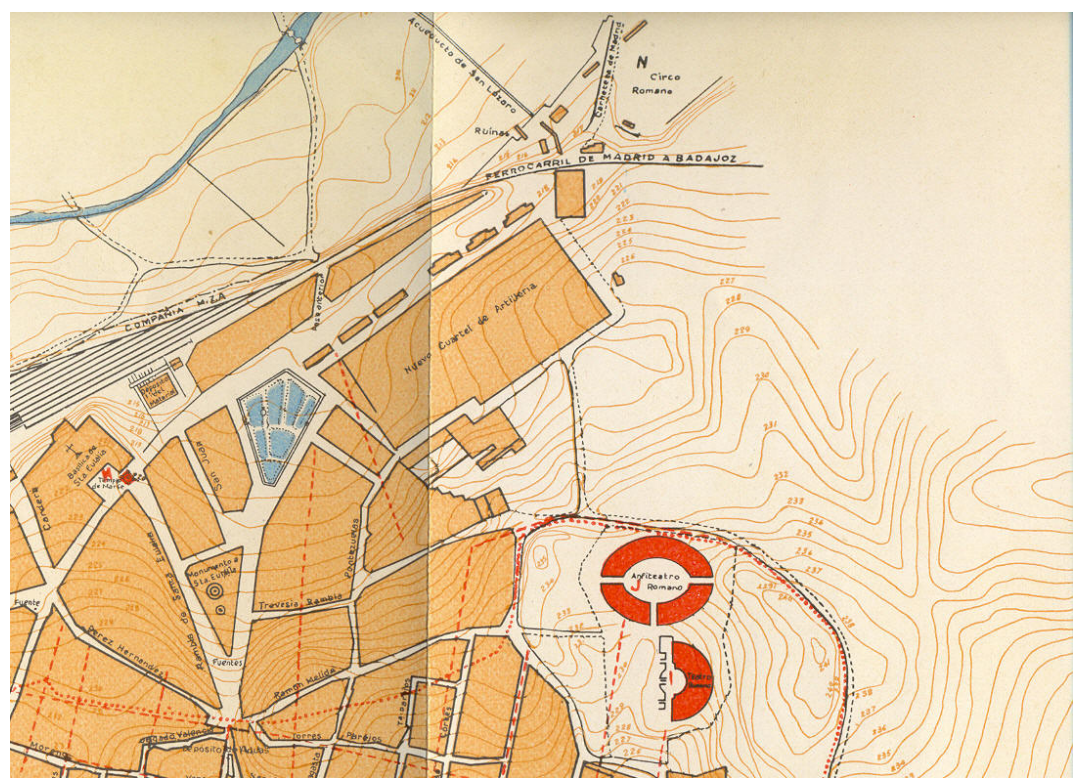

Fig. 1. Plano de Mérida aparecido en el libro de Maximiliano Macías Liáñez Mérida Monumental y Artística (Bosquejo para su estudio), publicado en el año 1929. Detalle de la zona perteneciente al circo romano, situada en el ángulo superior derecho de la imagen, que apenas es considerada por el autor más allá de su mera ubicación en el plano.

una ampliación en la zona sur, más allá del cinturón arqueológico, y dio lugar a una ansiada desviación: la de la carretera Madrid-Badajoz ${ }^{1}$.

\section{El entorno del circo romano}

Los alrededores de este imponente monumento romano serán un terreno por conquistar para el urbanismo de la primera mitad de siglo. La ciudad no había crecido por ese flanco, pues, a pesar de la necesidad que había de suelo edificable, la presencia de la vía ferroviaria que, según hemos visto, rodeaba como un cinturón toda la ciudad histórica y lo que, hasta el momento, habían sido las zonas de expansión, había dejado aislado dicho sector por el este (fig. 1). La ocupación del espacio aquí fue produciéndose de manera progresiva, en principio sobre suelos no urbanizables ${ }^{2}$, a base de viviendas de una y dos plantas -además de naves industriales- que iban cambiando, poco a poco, el aspecto de un espacio de gran importancia debido, en primer lugar, a las ruinas que albergaba, y, por otro lado, en lo que se refiere a vertebración urbana y de comunicaciones ${ }^{3}$.

Debemos tener en cuenta que, a principios del siglo XX, dicho entorno estaba ocupado por tierras de labor, como era relativamente habitual en parcelas ubicadas en las afueras poblacionales. Desde luego, la presencia del edificio romano dedicado a espectáculos ecuestres era conocida por la población desde siempre, fundamentalmente debido a la

1 Sobre la evolución socioeconómica y las transformaciones e intervenciones urbanísticas, teóricas y materializadas, del momento en Mérida, v. Castaño Fernández, 1989: 76-98. Doncel Rangel, 1991: 59-75. Barbudo Gironza, 2006: 170-214.

${ }^{2}$ Hay que tener en cuenta que antes del Plan General de Ordenación Urbana de 1954 dicho espacio no fue objeto de ninguna planificación oficial.

${ }^{3}$ A este respecto, Castaño Fernández argumenta que hay que tener en cuenta “(...) una decidida política de retención del suelo urbano por parte de los propietarios del mismo que se mantiene hasta finales de los años cincuenta, coincidiendo con los años de la autarquía": Op. cit., 89. 
monumentalidad y linealidad de los restos señalados en superficie ${ }^{4}$, aunque el interés suscitado por esta área tan extensa no pasaba, precisamente, por la conservación del yacimiento, sino por la utilización del terreno en parcelas agrícolas. Fue al hilo de la segunda década de siglo cuando, en un ambiente general de interés nacional por la arqueología y conservación del patrimonio, y tras haberse iniciado en la antigua urbe las excavaciones sistemáticas del teatro y anfiteatro, los otros dos grandes monumentos de la colonia -en 1910 y 1915, respectivamente-, le llegó el turno al circo.

A la hora de hablar de las intervenciones arqueológicas en la Mérida de principios de siglo es obligado referirnos al arqueólogo madrileño y director del Museo de Reproducciones Artísticas José Ramón Mélida Alinari (1856-1933) y al culto y bien relacionado erudito local Maximiliano Macías Liáñez (1867-1934) ${ }^{5}$, que fueron los dos grandes protagonistas de la recuperación patrimonial emeritense en la primera mitad de la centuria. Sus trabajos de excavación -junto con las correspondientes memorias- y los procesos de catalogación y conservación de los restos aparecidos continúan, aún hoy, siendo objeto de referencia en la arqueología nacional, dada la importancia de sus descubrimientos para el estudio del mundo romano.

Entre los años 1919 y 1920 sus trabajos para poder iniciar unas excavaciones oficiales que permitieran la recuperación, estudio y puesta en valor del importante monumento se materializaron en una serie de laboriosas negociaciones con los propietarios de los terrenos ocupados por tan vasto yacimiento ${ }^{6}$ que, a consecuencia de sus enormes proporciones -propias de un edificio imperial de estas características-, se situaba fuera de la primitiva muralla romana, junto a una de las principales vías que enlazaban la población con Corduba (Córdoba) y Toletum (Toledo). Aquí ya podemos apreciar la importancia estratégica de esta zona dentro de la antigua colonia, pues dicho camino comunicaba, a través de su encuentro con otros, directamente con el norte y sur de la península ${ }^{7}$. Esta decisiva ubicación hará que, a comienzos del siglo $\mathrm{XX}$, los restos arqueológicos de los que hablamos se encuentren junto a una vía fundamental para Mérida: la carretera nacional de MadridBadajoz.

Como hemos apuntado, el solar ocupado por el yacimiento pertenecía a varios particulares que, además, lo estaban explotando en gran parte de su superficie como tierras de labor. Ya en el siglo XIX, la implantación de la línea férrea junto a la franja occidental del yacimiento supuso una primera incursión de modernidad en la zona, donde uno de los problemas más acuciantes durante la primera mitad del posterior siglo XX será el de resolver el modo en el que la carretera de Madrid podría imbricarse en el entramado urbano. Evidentemente, se trataba de una cuestión fundamental, dado que dicha vía era una arteria principal de comunicación en una ciudad que iba creciendo -con el consiguiente aumento del caserío- y que, además, contaba con un patrimonio importante en dicho espacio urbano ${ }^{8}$. Atravesar esa

${ }^{4}$ El lugar era conocido por los habitantes de aquel momento -y aún en la actualidad- como la zona del Hipódromo o, incluso, la Carrera del Caballo: Barrera Antón, 1999: 130-137. Caballero Rodríguez, $2008: 357$.

${ }^{5}$ Licenciado más tarde en Filosofía y Letras, especializándose en Historia, se convirtió unos años antes en Correspondiente de la Real Academia de la Historia: Caballero Rodríguez, 2008: Op. cit., 467-468.

6 Tanto las tierras ocupadas propiamente por el yacimiento como los terrenos aledaños en la carretera de Madrid fueron objeto de desvelos para Mélida y Macías, de cara a emprender la excavación definitiva del circo. Al encontrarse -además de en explotación- en un lugar para el que se preveía una gran expansión urbanística -donde, entre otras edificaciones, se proyectaba la construcción cercana de los cuarteles-, sus propietarios supieron ver la oportunidad e intentaron sacar el máximo partido posible en las negociaciones de expropiación con el Estado y la compañía ferroviaria. El lector interesado podrá encontrar más información sobre esas negociaciones en Caballero Rodríguez, 2008: Op. cit., 313-317.

${ }^{7}$ La situación estratégica de un edificio de espectáculos como este era habitual en las ciudades romanas, que aprovechaban así la proximidad de caminos importantes a las entradas y salidas de las poblaciones para facilitar la asistencia del público. Para un estudio más pormenorizado de esta obra, v. Sánchez Palencia/Montalvo/Gijón, 2001: 75-95. Nogales Basarrate/Âlvarez Martínez, 2001: 217-232.

8 Además del circo, el inmediato acueducto de Rabo de Buey-San Lázaro también era un monumento romano a tener en cuenta; la ermita medieval de San Lázaro, sin embargo, no tuvo la suerte de ser considerada 


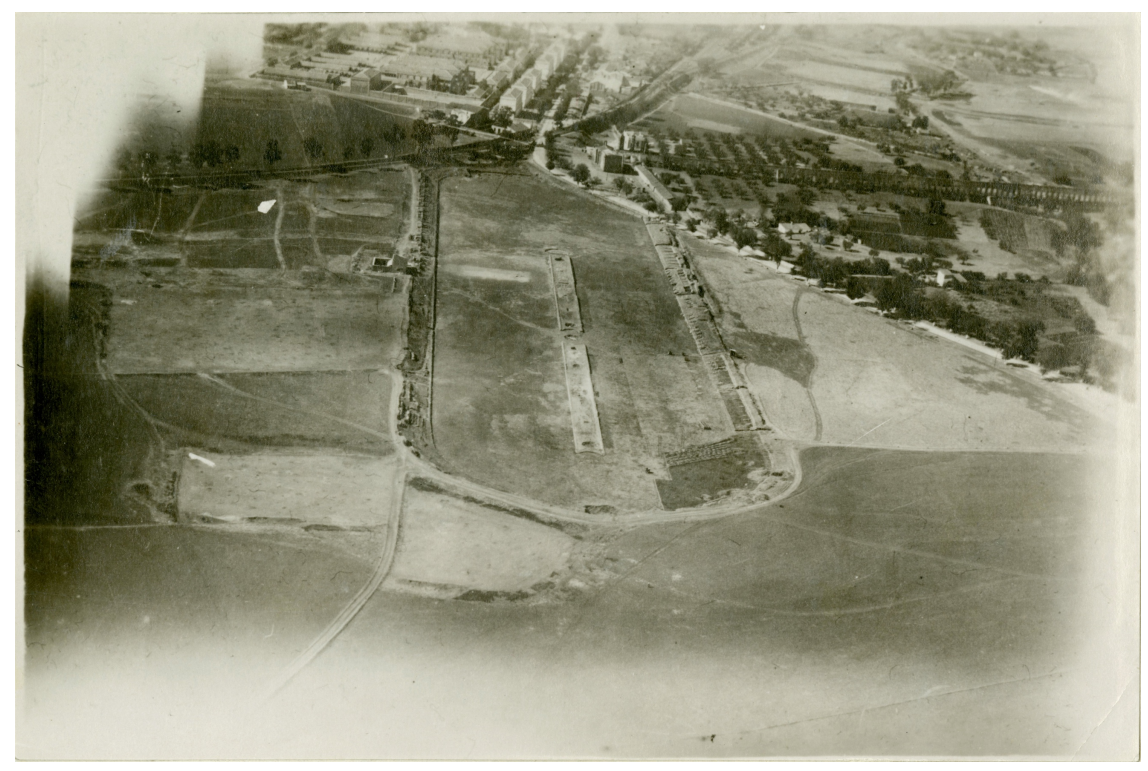

Fig. 2. Vista aérea del circo romano de Mérida. Circa 1930. Servicio fotográfico de la Sexta Sección de Aviación Militar (Getafe). Museo Nacional de Arte

franja urbana con la carretera o rodearla con una variante para facilitar el tráfico rodado por la ciudad será preocupación básica en los planes de intervención que se realicen en esta época? ${ }^{9}$.

Todo ello, en definitiva, nos habla de una situación estratégica para una zona que, con paso titubeante, se irá poblando progresivamente. A principios de los años treinta el entorno no presenta aún edificaciones (fig. 2). De forma paulatina, se irá ocupando con construcciones modestas y naves industriales, adquiriendo el aspecto de una zona de expansión poblacional, hasta que en los años cincuenta se habrá producido un aumento del caserío con viviendas de una o dos plantas, de diseño y materiales tradicionales. Será un poco antes de este momento cuando encontremos un proyecto que va a ser objeto de un estudio más pormenorizado por nuestra parte. El edificio que, a partir de él, se levante, nos demostrará que no solo serán viviendas sencillas las que ocupen por ahora dicho entorno. También las clases acomodadas escogerán esta área de incipiente crecimiento urbano para levantar sus viviendas unifamiliares, estableciéndolas, como suele ser habitual en este tipo de procesos $^{10}$, en unos lugares aún no planificados como urbanizables.

objeto de conservación y fue demolida hacia el año 1940, habiéndose autorizado ya cinco años antes a construir en el solar: Álvarez Sáenz de Buruaga, 1994: lám. 18 y p. 301, respectivamente. Para esta ermita, puede verse también a Barrera Antón, 1999: Op. cit., 140 y ss.

${ }^{9}$ Dentro del mencionado Plan General de Ordenación Urbana de 1954, el entorno que estudiamos logró tener como objeto de protección especial al circo. Tras varias propuestas e intentos, finalmente, la construcción del nuevo puente de Fernández Casado sobre el río Guadiana en el año 1960 materializará la tan ansiada desviación por el sur, bordeando la ciudad histórica, de tal manera que agilizaba definitivamente la circulación rodada y facilitaba la protección de la zona: Doncel Rangel, 1991: Op. cit., 72. En los años cincuenta, además, todavía se salvaba la línea del ferrocarril en las inmediaciones del circo por medio de un paso a nivel. Transcurrirán aún alrededor de veinte años hasta que se pueda eliminar y liberar a la vez el borde del monumento romano -mediante un paso inferior- de ser atravesado por lo que ya era la antigua Carretera de Madrid, hoy avenida de Juan Carlos I -Barbudo Gironza, 2006: Op. cit., 258-260-, pudiendo sacarse a la luz de nuevo entonces algunas de sus estructuras, como las cárceres.

${ }^{10}$ En algunas ocasiones, y como en cualquier otra ciudad, los planteamientos constructivos en la población lograron adaptarse a las soluciones aprobadas; sin embargo, en otras, las viviendas fueron escapando a todo 


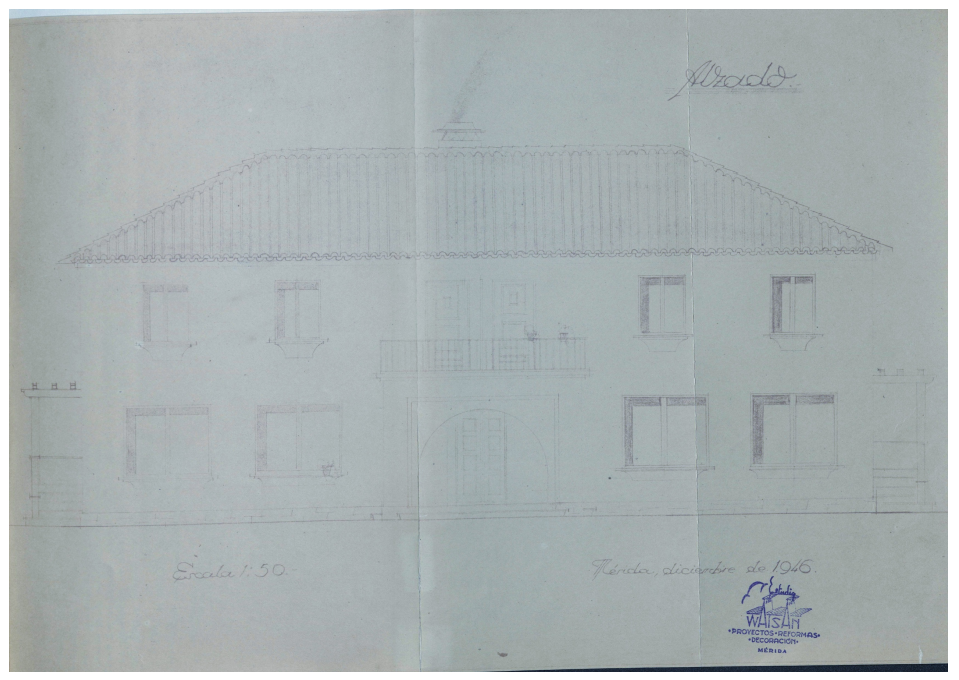

Fig. 3. Alzado del chalet para Féliz Lozano. Pedro Benito Watteler. 1946. Archivo Histórico Municipal de Mérida (AHMM).

\section{Proyecto de Pedro Benito Watteler}

Se trata, según figura en la memoria, de un proyecto de chalet en la llamada Carretera de Madrid, o zona de San Lázaro, en alusión al acueducto romano. Aparece fechado en diciembre de 1946 y está firmado por el arquitecto Pedro Benito Watteler. Nacido en 1908 y titulado en el año 1940, fue arquitecto municipal de Badajoz, realizando varias obras en su ensanche, además de otros trabajos en Madrid. Sus creaciones se encuadran fundamentalmente dentro del llamado estilo nacional propio de estas fechas, siendo algunas de sus construcciones más conocidas el Colegio de los Maristas, en la avenida Juan Pereda Pila, y el edificio de la Vasco Navarra, en Ronda del Pilar, ambas en la capital pacense. Así mismo, lleva a cabo en los años cincuenta edificios de viviendas en dicha población, con algunos resabios escurialenses, aunque muy matizados, como es el caso de un bloque de viviendas entre las avenidas de Huelva y de Santa Marina. Dentro de la arquitectura de corte religioso, cabe destacar su intervención en la portada de la Iglesia de la Soledad, en la plaza del mismo nombre, en el año 1951, realizando una puerta totalmente clásica en granito oscuro $^{11}$.

En el caso concreto que nos ocupa, el propietario del solar emeritense que albergará el proyecto de Watteler era Félix Lozano Pérez, vecino de Montijo, quien, según consta en la memoria, encarga al arquitecto un edificio de dos plantas, con tres viviendas, una en la baja -que ocupa toda la superficie de la construcción- y dos en la alta ${ }^{12}$, pudiendo deducirse que, o bien estaba pensado para el dueño y su familia, o bien pudo proyectarse en un principio con destino a inmueble de alquiler. Watteler, que se encontraba en 1946 prácticamente en los inicios de su carrera, realiza aquí un proyecto de corte tradicional, con planta cuadrangular cuyos únicos elementos sobresalientes serán un porche de entrada en la fachada principal y estructuras laterales para escaleras exteriores de acceso a las viviendas independientes de la planta alta (figs. 3, 4 y 5). La fachada se estructura en cinco calles, utilizando limpios vanos adintelados en todas ellas, siendo la central la más ancha y sobresaliente en planta, con puertas gemelas y balconada corrida en la planta alta y porche

control posible, como es el caso de las obreras, agrupadas en zonas con verdaderos criterios de hacinamiento, o, incluso, como estamos viendo, de las pertenecientes a clases acomodadas y sus viviendas unifamiliares.

${ }^{11}$ Lozano Bartolozzi/Cruz Villalón, 1995: 406 y 463. González González, 2002: 703; 2010: 42.

12 Con un coste de 100.000 pesetas y una superficie edificada de $171 \mathrm{~m}^{2}$, con cocina en la planta baja o principal de "fogón tipo Bilbao del número 6 y un fregadero de fábrica o piedra artificial" y cocinas, a su vez, en la planta superior "corrientes con hogares para carbón de encina": Proyecto de chalet en la carretera de Madrid (San Lázaro). Arquitecto D. Pedro B. Watteler. Propietario D. Félix Lozano Pérez, Mérida, diciembre de 1946, Archivo Histórico Municipal, Mérida (AHMM), Urbanismo, legajo 3226, carpeta 37, p. 3. 


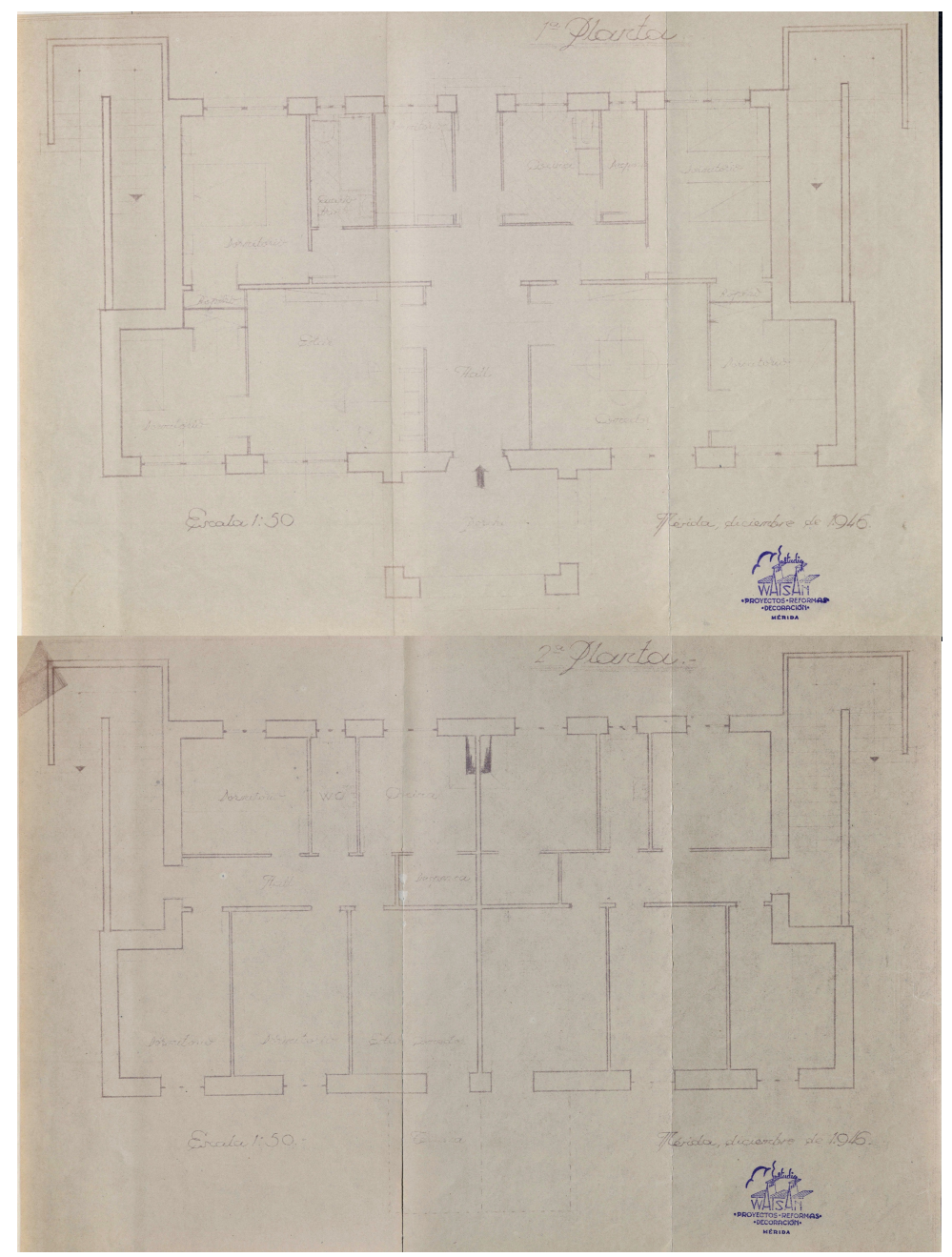

Fig. 4. Primera planta del chalet para Féliz Lozano. Pedro Benito Watteler. 1946. AHMM

Fig. 5. Segunda planta del chalet para Féliz Lozano. Pedro Benito Watteler. 1946. AHMM.

de entrada en ladrillo en la baja; será aquí únicamente donde utilice el medio punto en sus tres frentes; en el arranque de cada una de las escaleras gemelas en las fachadas laterales se sitúan sendas pérgolas de madera. El aspecto ornamental en fachada, por tanto, queda relegado por la severidad de líneas, apenas rota visualmente por el juego de planos que introduce el porche. Respecto a la cubierta, en el proyecto aparece a cuatro aguas y con teja árabe.

Dado que los materiales y técnicas constructivas son tradicionales ${ }^{13}$, nos encontramos ante un proyecto acorde con el estilo del arquitecto para estas fechas ${ }^{14}$, si bien la limpieza

13 "El forjado del piso de la planta alta será de bóveda tabicada por arista en todas las habitaciones, excepto en la alacena y pasillos donde se construirá de cañón"; "Las dos escaleras gemelas, exteriores, de acceso a las viviendas de la planta alta, se construirán a la catalana (...)"; "La carpintería de taller será de pino del país con cristales y herrajes corrientes (...)"; para el pavimento, en ambas plantas, se dispone "baldosín hidráulico, excepto los peldaños de las escaleras que serán de piedra artificial y en las dos plantas del porche, que será de baldosa sevillana."; "Los enlucidos de paramentos interiores y exteriores, serán de mortero de cal, lisos, excepto las fachadas, que irán fratasadas. El zócalo que circunda el edificio se enlucirá con igual clase de mortero imitando mampostería": Ídem, pp. 1-2.

${ }^{14}$ Los muros de mampostería ordinaria, las bóvedas tabicadas o la utilización de madera en las pérgolas nos hablan de un momento constructivo concreto donde la utilización de técnicas tradicionales se veía supeditada tanto al espíritu político concreto -en el que la utilización del ladrillo y la piedra remitía a la importancia del trabajo artesano tradicional- como a la escasez de hierro o a la falta de calidad del existente tras el conflicto civil, lo que, para evitar su utilización en un papel estructural, obligaba a soluciones como las que estamos tratando. Para más información, v. Llorente, 1995. 

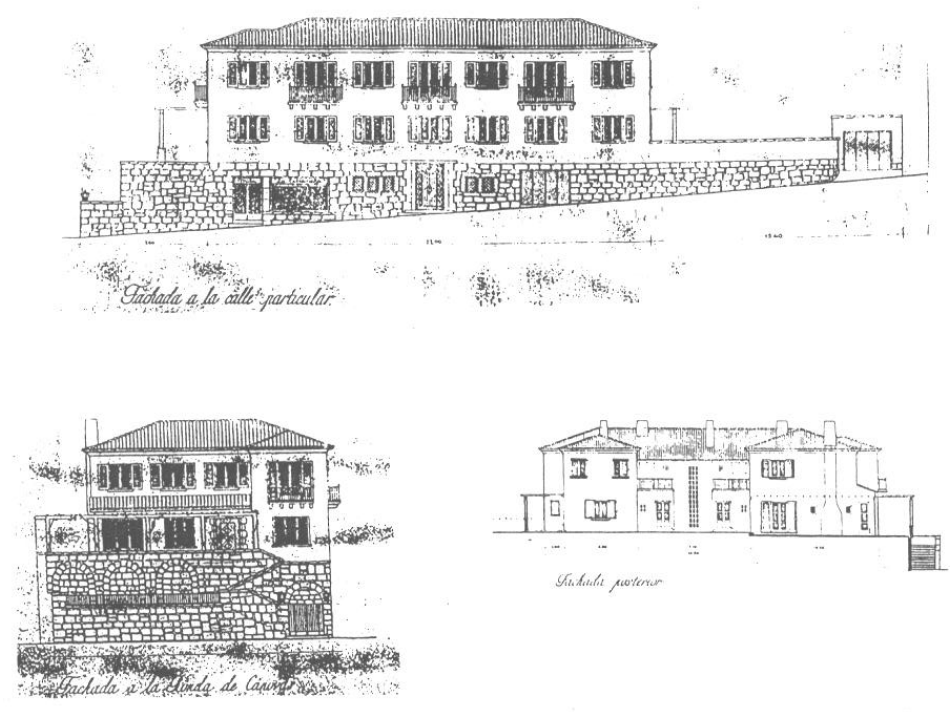

Fig. 6. Proyecto de chalet en la Avenida de Cánovas. Cáceres. Luis Gutiérrez Soto. 1940. Publicado en el libro de Lozano Bartolozzi/Cruz Villalón (1995): 452.

ornamental podría habernos situarnos en un plano algo más evolucionado, en un momento en el que cualquier conato de avance será frenado por la obligada mirada hacia una arquitectura más histórica. Respecto al tipo de distribución de vanos, el uso de unos materiales concretos, así como la utilización de pérgolas en las escaleras exteriores, nos recuerda una obra que, si bien realizada la nuestra con materias primas más modestas, se levantó en Cáceres unos años antes: el desaparecido chalet de Andrés Sánchez Torres, en el Paseo de Cánovas, firmado por el arquitecto madrileño Luis Gutiérrez Soto en junio de 1940 (fig. 6$)^{15}$.

Titulado en 1923 e incluido por Carlos Flores en la Generación de 1925, Gutiérrez Soto fue un arquitecto versátil, que se adaptó de manera práctica a los distintos momentos que le tocó vivir sin perder -a pesar de algunas de sus realizaciones en los años cuarenta, donde vuelve a un obligado e indefinido historicismo en ocasiones- su toque de originalidad y contemporaneidad con los avances de su tiempo. Sus edificios de viviendas para las clases medias-altas se convirtieron en un referente dentro de su obra y, así mismo, dentro de la producción arquitectónica nacional. Son viviendas con una distribución funcional de espacios y una utilización de materiales tradicionales y de hormigón armado que les confieren una personalidad muy característica, constituyendo elementos definidores -ya desde el inicio de su carrera- la solución de terrazas como ampliación de la zona principal de vivienda, la utilización de jardines posteriores o la presencia de pérgolas, tanto a terrazas y jardín como en la parte superior de los edificios. En Extremadura, Gutiérrez Soto intervino en varias ocasiones. En Badajoz realizó en 1940 el cortijo de la finca "La Orden", además de dos edificios para viviendas -ya con una tipología más madura- en la década de los cincuenta: las

15 Sobre esta y otras construcciones de Luis Gutiérrez Soto en la región extremeña, v. Lozano Bartolozzi/Cruz Villalón, 1995: Op. cit., 450-452. 


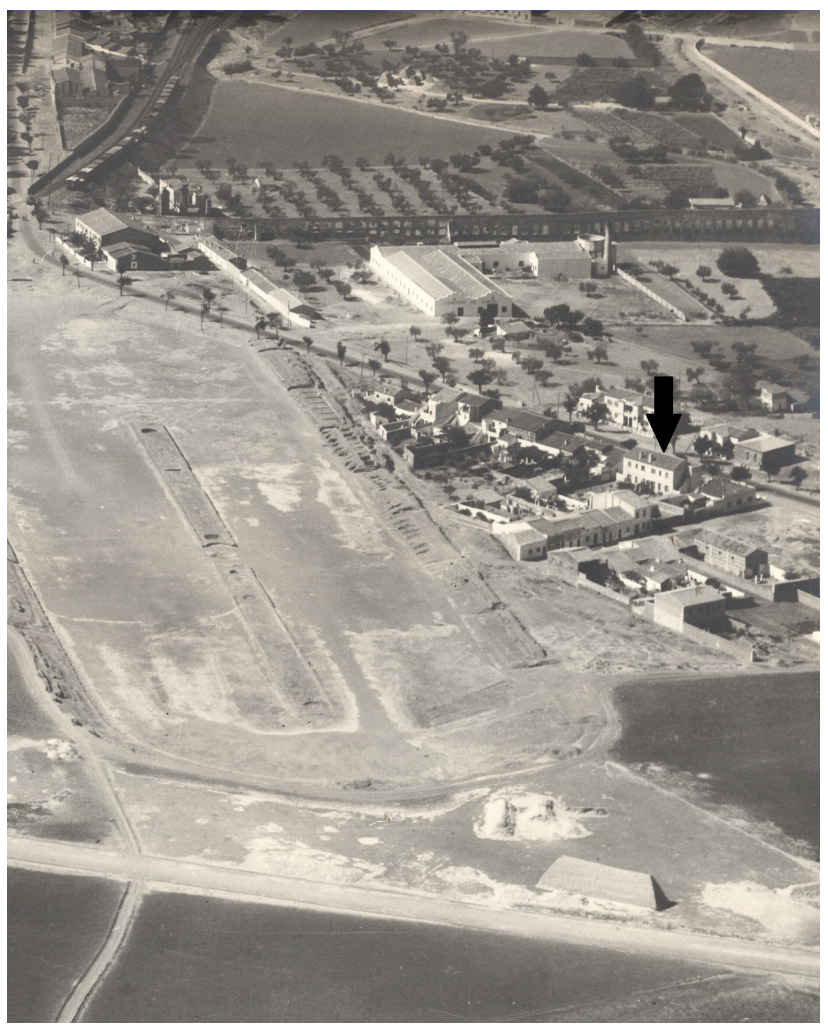

Fig.7. Por menor de una vista aérea correspondiente a la zona del circo romano. 1954. AHMM. Hemos señalado el edificio levantado según el proyecto de Pedro Benito Watteler con una flecha, a la derecha de la imagen, para una mejor localización.

\section{Casas de Vecindad de la Avenida de Enrique Segura Otaño (1954) y la de la Avenida de Huelva (1958) ${ }^{16}$.}

Los proyectos para Cáceres son más tempranos que los que crea para la capital pacense. Concretamente, en el año 1939 diseñó una casa de campo en la finca "La Redondilla" para Joaquín Sánchez Torres, familia perteneciente a la alta burguesía de la ciudad con la que el arquitecto estaba muy relacionado. Poco después, en 1944, realizará el nuevo edificio de la Banca Sánchez, en la calle Pintores y, entre ambos, y siempre para la misma familia, proyecta el mencionado chalet del Paseo de Cánovas, al que nos hemos referido más arriba.

Se trataba de una casa de vivienda propia y pisos de alquiler, de tres plantas con cochera y tienda. Evidentemente, nos encontramos ante un edificio más grande que el de nuestro proyecto, hecho con materiales de primera calidad $^{17}$, pero la semejanza en cuanto a la utilización de estos - con cubierta de teja árabe incluida-, la distribución de vanos en fachadas e, incluso, la presencia de pérgolas, nos hablan de la existencia de un modelo concreto de chalet para viviendas pertenecientes a clases acomodadas que Pedro Benito Watteler pudo conocer, bien propiamente a través del chalet de los Sánchez cacereño, realizado unos años antes que nuestro proyecto, o bien a través del trato con el mismo arquitecto y/o su obra madrileña, puesto que ambos profesionales trabajaron en la capital española ${ }^{18}$.

Volviendo a terreno emeritense, el trabajo de Pedro Benito Watteler se encuadraría, por tanto, dentro de una tipología concreta de viviendas acomodadas, en este caso situadas en zonas de expansión urbana, en un momento, además, en el que las dificultades económicas,

16 Para el caso de estos edificios de viviendas, v. el trabajo de González González, 2001: 105-109.

17 Mientras que en el chalet cacereño, por ejemplo, además del uso abundante de hormigón armado, los muros exteriores hasta el nivel de la primera planta eran de mampostería vista, en el caso de nuestro proyecto emeritense el zócalo circundante iba enlucido con mortero imitando mampostería; en cuanto a la carpintería, en el primer edificio eran de madera de castaño y en el segundo de pino del país.

18 Casualmente, el proyecto de Luis Gutiérrez Soto es de 1940, el mismo año en el que Pedro Benito Watteler sale de las aulas. 


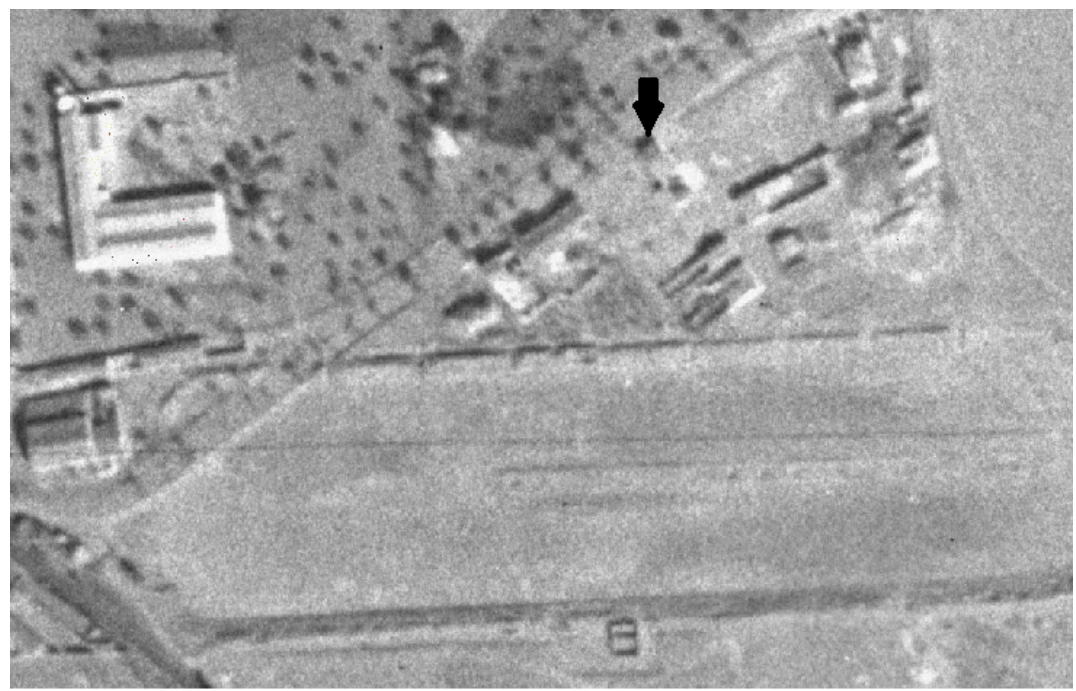

Fig. 8 Imagen perteneciente al vuelo americano sobre la Península Ibérica de 1945-46. Detalle de la zona perteneciente al Circo. Consultado en $<$ https://fototeca.cnig.es/> [Noviembre de 2016]. El edificio que nos interesa en esta ocasión queda señalado con una flecha.

en España, en general, y, en Mérida, en particular, hacían doblemente loables trabajos de este tipo. Sin embargo, el edificio, como tantos otros, fue demolido y, a mediados de los años 80, se levantó en su ubicación un bloque de pisos, lo que ha privado a la ciudad de esta obra representativa de una época. Desgraciadamente, no hemos podido encontrar fotografías que nos permitan ver el inmueble tal y como se construyó, a excepción de una imagen conservada en el Archivo Histórico Municipal de Mérida correspondiente al año 1954 en la que aparece a bastante distancia (fig. 7), aunque, a través de ella, podemos hacernos una idea clara de la presencia visual que pudo tener en una vía de expansión como esta. Además, junto a la obra en sí, nos queda el conocimiento de una presencia reseñable para cualquier ciudad de provincias en aquel momento: la existencia del Estudio Watsan, de donde surge esta edificación, cuyo sello se hacía acompañar de la leyenda Proyectos. Reformas. Decoración. Mérida, que estuvo ubicado en la calle Alvarado, número 10, en pleno centro de la población.

Resulta muy interesante el hecho de que en una época de escasez económica como era el año 1946 y en una ciudad pequeña como era el caso de Mérida, que hacía aún más complicada la existencia de empresas privadas que tomasen la iniciativa a la hora de hablar de vivienda, haya un estudio del que salgan este tipo de proyectos. Evidentemente, los trabajos que surgirían de este lugar estarían encaminados a la clases medias-altas, que eran las que podían permitírselos y las que, con sus encargos, hacían posible su existencia, pero, aun así, si tenemos en cuenta el momento histórico y el tamaño de la población, su valor es importante.

\section{Proyecto de Narciso Rodríguez}

Con el paso de los años, y a través de las fotografías correspondientes a la zona, podemos ir comprobando cómo las instalaciones industriales continúan conviviendo con casas unifamiliares para población modesta, en unos casos, y para clases acomodadas, en otros, que se van a suceder progresivamente en la década de los cincuenta, en un entorno en el que la creación de una red de saneamiento público iba muy por detrás del ritmo de las 


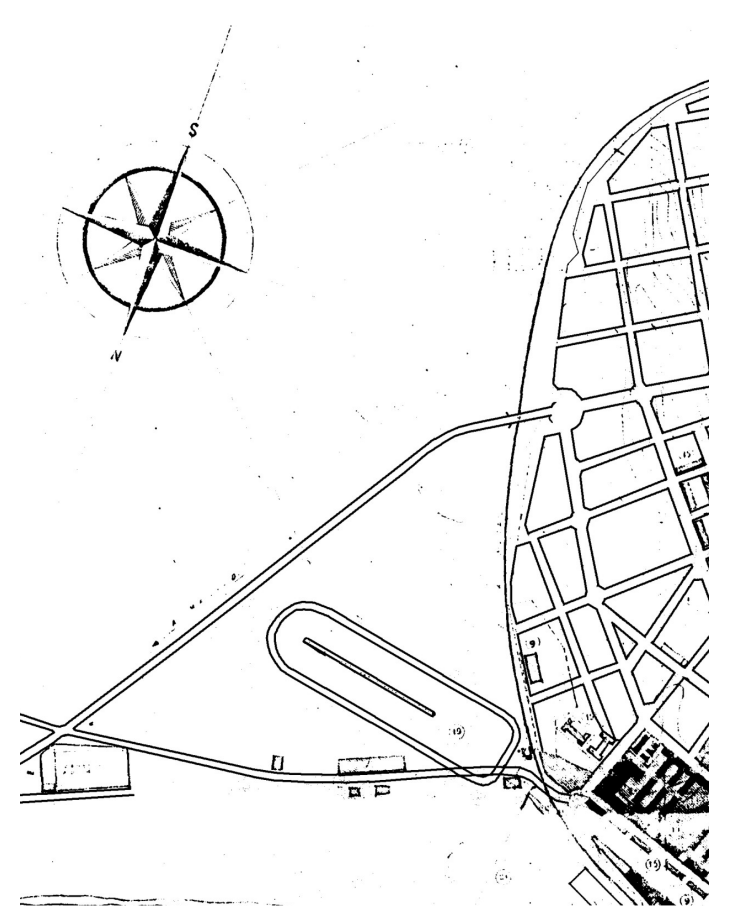

Fig. 9. Proyecto de Ordenación y Reforma Urbana de 1949. Zona del Albarregas. Detalle de la zona correspondiente al circo romano. Sobre un plano general correspondiente, a su vez, al Proyecto de Ordenación y Reforma Urbana de 1946. Cortesía de Barbudo Gironza. V. Barbudo Gironza, 2006: 184. Obsérvese que aparecen muy pocas construcciones aún, pudiendo ser una de ellas la que nos interesa en este momento. Además, en este plano podemos ver la proyección de la nueva variante de la carretera de Madrid que, en sustitución de la existente -que tocaba y atravesaba el Circo en la zona de las cárceres- se iba a prolongar, atravesando el Guadiana por un nuevo puente.

edificaciones ${ }^{19}$. En unas ocasiones, serán viviendas adosadas y, otras veces, exentas, donde, a pesar de la presencia del típico jardín delantero y tipología y materiales tradicionales, se irán introduciendo tímidamente leves aires de renovación, apenas perceptibles, como serán cierta pureza general en cuanto a líneas y, por ejemplo, la presencia de plantas curvas en algún balcón o esquina.

Algo más de una década después de firmada la obra de Watteler, concretamente, en marzo del año 1959, encontramos un permiso de obras para reforma del chalet-según figura en la memoria- propiedad de Diego Lozano Rodríguez, sito en la Carretera de Madrid, n. 24, firmando esta vez el proyecto en la capital de España, en enero de ese mismo año, el arquitecto Narciso Rodríguez. Se trata del solar contiguo al que hemos estudiado previamente, donde ya había una casa que ahora se trata de reformar, pertenecientes los dos predios al mismo propietario ${ }^{20}$. Evidentemente, nos encontramos ante la edificación en dichas fincas por parte de una misma familia, correspondiéndole la construcción en 1959 ya al hijo, en un terreno que originalmente había sido de sus padres; como elemento meramente anecdótico, citaremos que nos hallamos en este segundo proyecto ante el conocido en Mérida como "chalet de Lozano", por ser su propietario el jugador del Atlético de Madrid Diego Lozano.

Si observamos las imágenes que hay del vuelo americano correspondiente a los años 194546 (fig. 8), en la instantánea que recoge esa zona ya aparece un edificio en dicho solar; sin embargo, no figura en fotografías existentes de años anteriores, como la realizada por el Servicio Fotográfico de Aviación Militar, del año 1930, con lo que la construcción de la vivienda previa debió llevarse a cabo en esa misma década de los treinta o a comienzos de la siguiente (fig. 9). Gracias a la imagen ya mencionada del año 1954, conservada en el Archivo Histórico Municipal, conocemos que el inmueble que existía previamente era una vivienda de corte tradicional con una sola planta, tejado a tres aguas, un pequeño espacio delantero dedicado a jardín y patio posterior. La fachada lateral que puede apreciarse en la fotografía

19 Tengamos en cuenta que hasta mediados de los años sesenta no empieza a introducirse en esta vía la red pública de saneamiento.

${ }^{20}$ En la ya estudiada memoria del proyecto de Watteler aparece Félix Lozano Pérez como dueño de los dos predios: p. 3. 


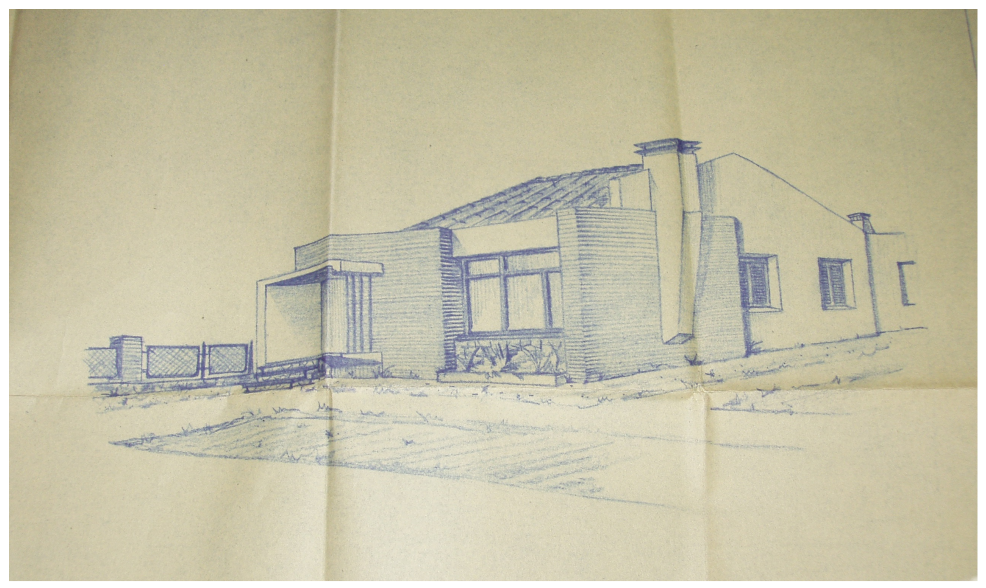

Fig..10. Dibujo que abre la planimetría correspondiente a la memoria de la reforma del chalet de Diego Lozano. Narciso Rodríguez. 1959. AHMM.

se estructuraba en tres calles con vanos cuadrangulares y en el remate de los muros se procedía por medio de la clásica solución tripartita a diferentes alturas en dos de sus frentes y líneas escalonadas en otro. En suma, se trataba de un espacio total rectangular, ocupando el chalet propiamente dicho una superficie aproximada de $90 \mathrm{~m}^{2}$, cuyo frente principal daba a la Carretera de Madrid (hoy Avenida de Juan Carlos I) y uno de los laterales a la actual calle de Cuacos de Yuste ${ }^{21}$. Hablamos, por tanto, de una casa unifamiliar que -si tenemos en cuenta el aspecto exterior y su distribución interna ${ }^{22}$ - fue concebida de manera más sencilla en su conjunto que la que vendrá después.

Narciso Rodríguez fue el arquitecto encargado, como decimos, de reformar esta casa. Nacido en 1923, se titula en Madrid en el año 1958. Hijo del teniente coronel Narciso Rodríguez Ramírez -de idéntico nombre que su hijo y alcalde de Mérida entre 1955 y 1958-, se doctorará en el año 1966, siendo nombrado Colegiado de Honor por el Colegio Oficial de Arquitectos de Extremadura poco antes de su fallecimiento en el año $2009^{23}$. Cuando Narciso Rodríguez realiza el proyecto que estamos tratando hace un año que ha salido de las aulas, por lo que está iniciando una trayectoria profesional en este preciso momento con el peso lógico de todo el bagaje teórico adquirido en su formación.

La intervención en la finca de Lozano tenía como criterio vertebrador “(...) lo obligado de conservación de cubierta, y situación fija del perímetro mural como consecuencia de la misma (...)"24. Por lo tanto, ajustándose a dicha premisa, la estructura constructiva no variará en lo esencial respecto al edificio existente ${ }^{25}$, aunque la reforma consista específicamente "(...) en una nueva distribución interior y como consecuencia de la misma en el exterior (...) ${ }^{26}$. Para ello, el arquitecto procurará redefinir claramente las tres zonas habitables de la casa, es decir, acceso y recibimiento -formada por vestíbulo y sala de estar-, los dormitorios -tres- y cuarto de baño, y la zona de servicio -constando de comedor, cocina y

21 Proyecto de chalet en Mérida. Propietario: D. Diego Lozano Rodríguez. Chalet: Carretera de Madrid. Arquitecto: Narciso Rodríguez, Madrid, enero de 1959, AHMM, Urbanismo, legajo 3670, carpeta 2.

22 Ibídem.

23 "El Colegio Oficial de Arquitectos de Extremadura, COADE, nombra nuevos arquitectos honoríficos". En Revista Habitex. Arquitectura y Ciudad, n. 35, Cáceres, junio, 2009: 4.

24 Proyecto de chalet en Mérida, Narciso Rodríguez, 1959, p. 2.

25 “ (...) estando formada por unos pilares y dos muros de carga en los lados pequeños del rectángulo que forma el chalet, ya que la misma es la que sostiene la cubierta que ha permanecido igual en dicha reforma.": Ídem, p. 3.

26 Ídem, p. 1. 


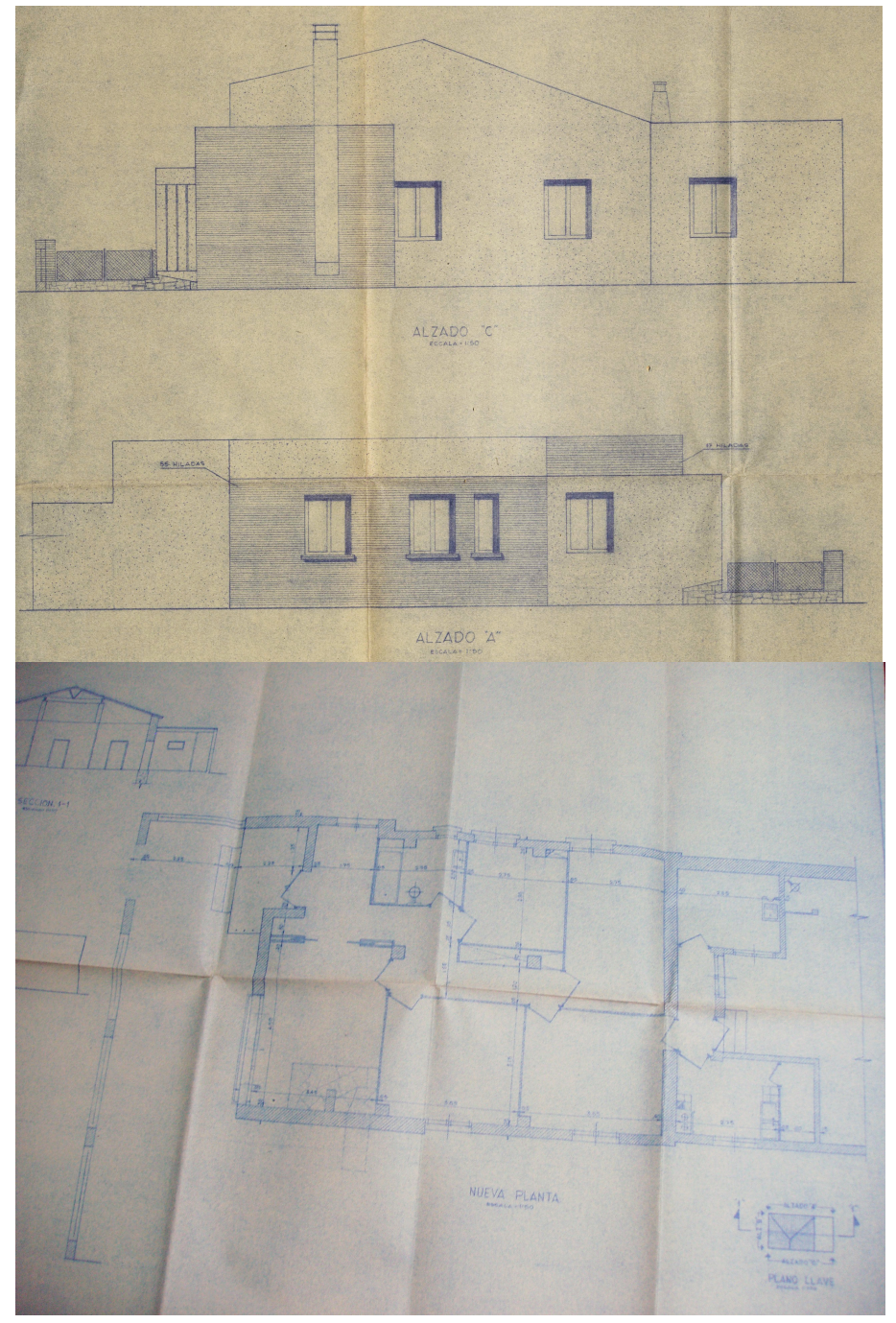

Fig. 11. Proyecto de Narciso Rodríguez. 1959. Alzados. AHMM

Fig. 12. Proyecto de Narciso Rodríguez. 1959. Planta de la reforma. AHMM.

lavadero-, así como la relación entre ellas mediante un pasillo y hall de distribución. En lo referente al exterior, Narciso Rodríguez se decanta, en aras de una perseguida sencillez, por el juego de volúmenes en fachadas y el contraste cromático que ofrecía la utilización de diferentes materiales constructivos (figs. 10, 11 y 12).

El arquitecto realiza aquí una obra adscrita a los postulados básicos del Movimiento Moderno en España correspondientes a finales de la década de 1950, con el Estilo Internacional como horizonte (fig. 13). Evidentemente, volvemos a repetir, al tratarse de una reforma en la que deben conservarse tanto la cubierta como los límites perimetrales, estos últimos a consecuencia de la misma, el autor tiene un campo bastante limitado de acción (fig. 14), introduciendo su visión de lo que significaba la arquitectura moderna fundamentalmente en la fachada principal y en algún elemento no estructural como es la chimenea, ubicada en una fachada lateral (fig. 15). Así, las conocidas premisas del Movimiento Moderno sobre la planta o fachada libres quedan aquí imposibilitadas, reflejándose, por ejemplo, -y, como consecuencia, también- un más que tímido intento por ofrecer una proyección longitudinal de ventanales en la fachada principal que queda aquí muy reducida en sus dimensiones, dado el escaso espacio al que adaptarse. No obstante, a pesar de las limitaciones estructurales impuestas, el espacio interior se articulará de manera más dinámica respecto a la construcción previa, confluyendo en un espacio de distribución de planta más libre, “(...) de forma que haya independencia entre las mismas [las tres zonas] a la vez que la relación indispensable en lo funcional, de toda vivienda teniendo en cuenta las necesidades particulares de su morador 


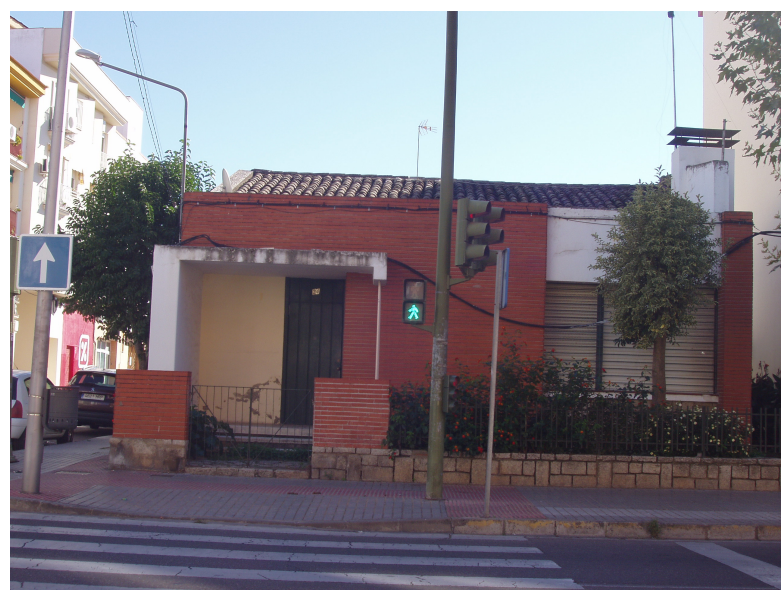

Fig. 13. Fachada principal de la vivienda proyectada para Diego Lozano en la actualidad, correspondiente a la Avenida de Juan Carlos I.

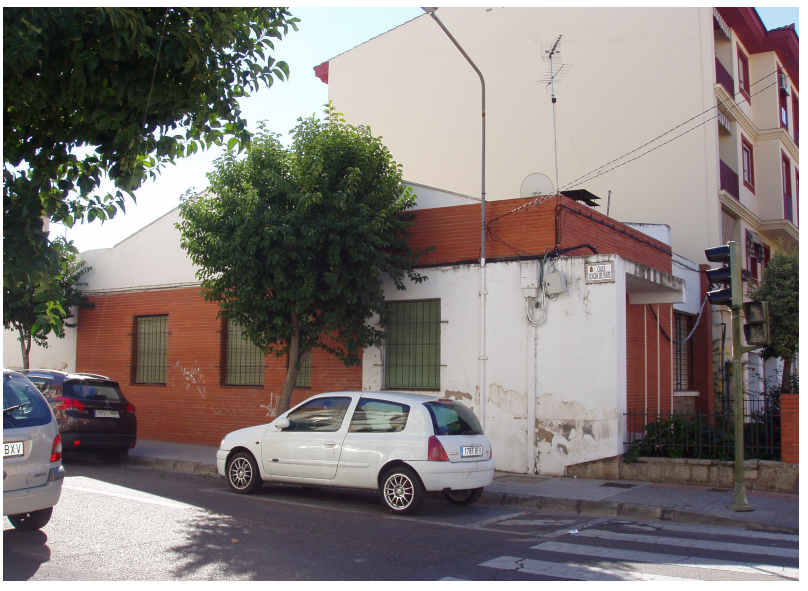

Fig. 14. Fachada lateral de la vivienda proyectada para Diego Lozano en la actualidad, correspondiente a la calle Cuacos de Yuste.

propietario." ${ }^{27}$; se trata de intentar una adaptación del espacio a la comodidad de los ocupantes, entendiéndose en este caso, lógicamente, el término "funcional" como integridad y utilidad del diseño, sin hacer referencia a los materiales.

Respecto a estos últimos, el arquitecto utiliza -junto al hormigón- algunos tan tradicionales como pueden ser la mampostería de piedra, el ladrillo o la cal. El uso de los mismos no ha dejado de estar vigente en la arquitectura española, no solo ya de posguerra -donde escaseaba, como hemos visto, el hierro-, sino que, con anterioridad, arquitectos tan renovadores del espíritu de la vivienda unifamiliar como fueron Zuazo y Bergamín ya emplearon estos materiales en sus construcciones de manera convencida. Por lo tanto, a la vez que el hormigón armado, estos elementos tendrán presencia habitual en casas unifamiliares que se construyan en la década de los cincuenta, a la vez que la teja o los pavimentos cerámicos, donde se mezclará un nuevo racionalismo con la mirada hacia la arquitectura popular, atraídos los artistas por su libertad de formas y adecuación a las necesidades del terreno. Coderch, Corrales o de la Sota son solo unos ejemplos ${ }^{28}$.

De todos es conocido que las viviendas unifamiliares son laboratorios magníficos para ensayar nuevas técnicas constructivas o de utilización de materiales, tanto por la idoneidad de sus medidas como por tratarse de estructuras presentes en toda época y lugar. En ellas se mezclarán tendencias variadas en unos momentos de búsqueda y efervescencia creadora, unas veces experimentadas por el propio arquitecto y otras muchas, como el caso de nuestro país, inspiradas en debates de arquitectura ${ }^{29}$, publicaciones o revistas procedentes del extranjero, fuente ansiada y constante esta última de proyectos en una nación que se iba abriendo a duras penas al influjo exterior. Para el caso que nos ocupa, el hecho de reformar una vivienda previa ofrecía al arquitecto una posibilidad interesante de conjuntar de una manera personal la limpieza en el diseño de los postulados racionalistas con la sencillez compositiva de una casa de corte tradicional, mentalidad que, como hemos comentado, no era ajena a la época.

En el chalet de Diego Lozano, Narciso Rodríguez -recordemos, un autor recién licenciado- introduce unos elementos significativos a los que él mismo hará referencia

\footnotetext{
27 Ídem, p. 2.

28 Beguiristáin Repáraz, 2000: 181-193.

${ }^{29}$ Esteban Maluenda, 2000: 241-250.
} 


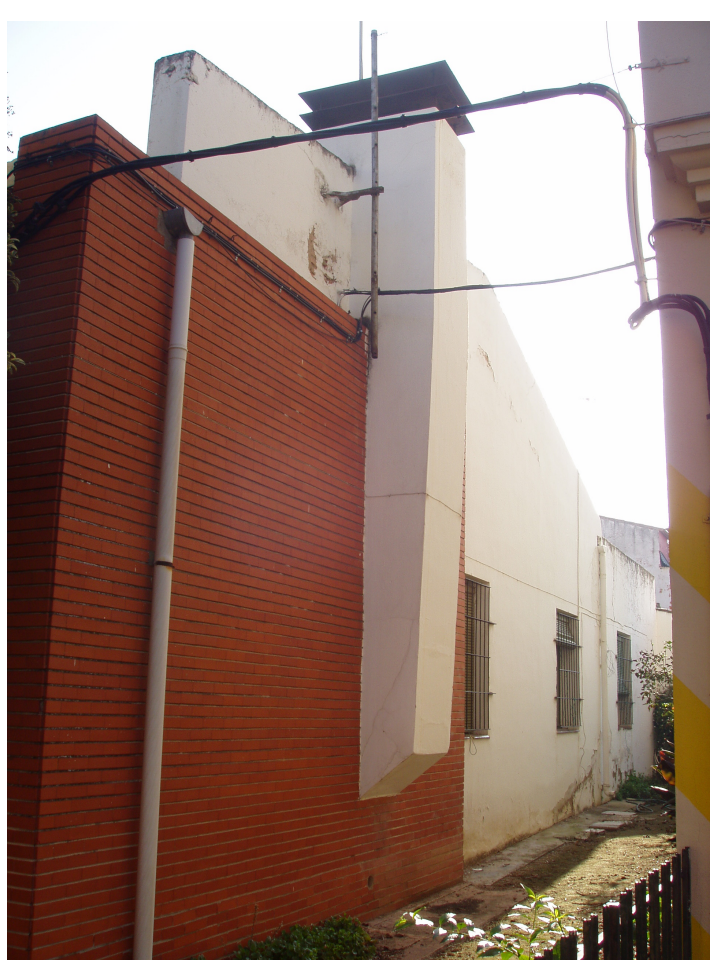

Fig. 15. Fachada lateral de la vivienda proyectada para Diego Lozano en la actualidad, correspondiente al jardín lateral de desahogo. Vista de la chimenea.

expresa en su memoria, que nos evidencian el eclecticismo estético -característico, por otra parte, en las obras de este momento en nuestro país- en el que se mezclan elementos de diferente origen. En el caso del blanco porche cúbico de ingreso a la vivienda, de un volumen neoplasticista -que apoya en uno de sus lados sobre tres tubulares de hierro pintados en el mismo color-, nos puede traer ciertos recuerdos de algunas obras pertenecientes al primer racionalismo italiano ${ }^{30}$, propio de su formación madrileña; para la chimenea correspondiente a la sala de estar -de poderosa presencia en una de las fachadas laterales- y su conjunción con la techumbre de teja, se nos vienen a la mente ciertas obras de Coderch e, incluso, de su discípulo Federico Correa, en una mirada hacia la vertiente catalana y su amor por la arquitectura mediterránea. Narciso Rodríguez también mencionará en su memoria como elemento digno de destacarse el hastial que, junto a la chimenea, cierra la cubierta por esa parte, lo que nos traslada su claro espíritu diferenciador de la estética tradicional con la que en esta obra convive. El hecho de utilizar también, como estamos viendo, una fachada con planos sobresalientes en planta y sus consiguientes juegos lumínicos, que amplían las diferencias de texturas en los materiales, nos sitúa, así mismo, en la órbita Movimiento Moderno. En definitiva -y sin olvidarnos en ningún momento de que estamos ante un ejemplo de provincias-, nos encontramos ante una obra ecléctica cuyo estudio creemos que resulta interesante, además, por tratarse de una reforma de chalet, circunstancia que el autor sabe aprovechar a la hora de compaginar las concepciones tradicionales y modernas en un conjunto que tenía unas limitaciones considerables ya fijadas de antemano.

${ }^{30} \mathrm{~V}$. la obra de Giuseppe Terragni. Este porche de entrada, denominado por el propio arquitecto como "el dado", representa, en palabras del autor, un intento de aportar "(...) una cierta gracia, que dé un aspecto agradable y moderno al chalet (...)”: Proyecto de chalet en Mérida, Narciso Rodríguez, 1959, p. 2. 


\section{Conclusiones}

A lo largo de poco más de una década, correspondiente a los años centrales del siglo XX, hemos estudiado el levantamiento en Mérida de dos tipos diferentes de chalets para clases acomodadas en un mismo espacio urbano, en una zona tan compleja como es un entorno arqueológico de grandes dimensiones ubicado a las afueras de la tradicional ciudad histórica. Estos ejemplos nos han hablado de la utilización de unos terrenos para edificar casas particulares por parte de una familia acomodada, que se asienta aquí en el momento justamente anterior a aquel en el que se iba a producir la expansión de la ciudad milenaria hacia esa zona, construyéndose las viviendas en un lugar en el que aún no existía la enorme presión demográfica que vendrá a partir de los años sesenta.

Evidentemente, nos hemos acercado a una ciudad de provincias, con todo lo que ello supone a la hora de referirnos a su ubicación dentro del panorama socioeconómico y, por ende, arquitectónico, nacional, y hemos escogido dos edificios encargados por un sector concreto de la población que, en esos momentos, tuvo capacidad económica suficiente para plantear inmuebles con unas determinadas pretensiones dentro del panorama general de la ciudad. En el primero de los casos, el edificio de dos plantas con tres viviendas proyectado por Watteler, nos resulta un ejemplo interesante por su vinculación con una tipología concreta que, para viviendas de clases acomodadas, están realizando en otras ciudades españolas arquitectos como, por ejemplo, Luis Gutiérrez Soto. Por su parte, la reforma de chalet llevada a cabo por Narciso Rodríguez, traslada a una vivienda previa de carácter tradicional toda la renovación de la que el joven arquitecto es capaz dentro del limitado campo de acción derivado de toda reforma, resultando una vivienda ecléctica en la que el Movimiento Moderno pugna por alcanzar el protagonismo.

El hecho de que uno de estos edificios haya desaparecido y el otro se encuentre "asfixiado" en la actualidad por los inmuebles circundantes no les resta su valor pionero en un momento difícil para la arquitectura española, en general, y de provincias, en particular, convirtiéndolos en representaciones tipológicas de dos formas diferentes de ver las viviendas destinadas a familias acomodadas en una zona de expansión. El movimiento de la ciudad de ahora en adelante, como algo vivo que es, será el que decida sobre la conservación, o no, para su futuro, de la parte de historia que aún se mantiene en pie representada en este conocido en Mérida como "chalet de Lozano". 
Bibliografía

Álvarez Sáenz De Buruaga, J.: Materiales para la Historia de Mérida (de 1637 a 1936). Mérida: Diputación Provincial de Badajoz y Ayuntamiento de Mérida. (1994)

Barbudo Gironza, F.: Mérida, su desarrollo urbanístico. Desde los planos de alineaciones al Plan Especial del Conjunto Histórico-Arqueológico. Badajoz: Asamblea de Extremadura. (2006)

Barrera Antón, J. L. de la: Estampas de la Mérida de Ayer. Mérida: Asociación de Amigos del Museo Nacional de Arte Romano. (1999)

Beguiristáin Repáraz, Í.: "La vivienda unifamiliar y la búsqueda del ideal orgánico: una experiencia truncada". En POZO MUNICIO, José Manuel (Coord.) (2000): Los años 50: La arquitectura española y su compromiso con la historia. Pamplona: Escuela Técnica Superior de Arquitectura. Universidad de Navarra, (2000), pp. 181-193.

Caballero Rodríguez, J.: Maximiliano Macías y su tiempo (1867-1934). Historia intima de las grandes excavaciones en Mérida. Mérida: Ed. Artes Gráficas Rejas. (2008)

Castaño Fernández, F. J.: Los paisajes urbanos de Mérida. Una introducción a su estudio geográfico. Mérida: Patronato de la Biblioteca Pública Municipal Juan Pablo Forner. (1989)

Doncel Rangel, J.: Mérida, bistoria urbana (1854-1987). Mérida: Ayuntamiento de Mérida. (1991)

Esteban Maluenda, A. Ma: “¿Modernidad o tradición? El papel de la R.N.A. y el B.D.G.A. en el debate sobre las tendencias estilísticas de la arquitectura española". En POZO MUNICIO, José Manuel (Coord.) (2000): Los años 50: La arquitectura española y su compromiso con la historia. Pamplona: Escuela Técnica Superior de Arquitectura. Universidad de Navarra, (2000), pp. 242-250.

González González, J. M.: Arquitectura contemporánea en Extremadura. Mérida: Editora Regional de Extremadura; González González, José Manuel (2001): "Arquitecturas de los cincuenta. La presencia en Badajoz de Luis Gutiérrez Soto". En VV.AA. (2001): Curso Apuntes para la Historia de la ciudad de Badajoz: T. III. Badajoz: Ed. Real Sociedad Económica Extremeña de Amigos del País, pp. 105-109; González González, José Manuel (2002): "Ecos escurialenses en la ciudad de Badajoz: la arquitectura de los años cincuenta". En Campos Y Fernández De Sevilla, Francisco Javier (Coord.) (2002): El Monasterio del Escorial y la Arquitectura. San Lorenzo de El Escorial, Madrid: Instituto Escurialense de Investigaciones Históricas y Artísticas, (2010), pp. 697-704.

Lozano Bartolozzi, Mª M. y Cruz Villalón, M.: La arquitectura en Badajozy Cáceres. Del eclecticismo fin de siglo al racionalismo (1890-1940). Villanueva de la Serena, Badajoz: Asamblea de Extremadura. (1995)

Llorente, A.: Arte e ideología en el franquismo (1936-1951). Madrid: La balsa de la Medusa (Visor Distribuciones). (1995)

Nogales Basarrate, T. y Álvarez Martínez, J.M.: "Espectáculos circenses en Augusta Emerita. Documentos para su estudio". En Nogales Basarrate, T./Sánchez Palencia, F.J. (Coord.) (2001): El Circo en Hispania Romana. Madrid: Ministerio de Educación, Cultura y Deporte, (2001), pp. 217-232.

Sánchez-Palencia, F.J., Montalvo, A. y Gijón, E.: "El Circo romano de Augusta Emerita". En Nogales Basarrate, T./Sánchez Palencia, F.J. (Coord.) (2001): El Circo en Hispania Romana. Madrid: Ministerio de Educación, Cultura y Deport 